REVISTA ANDALUZA DE ANTROPOLOGÍA.

NÚMERO 12: PATRIMONIO INMATERIAL: REDUCCIONISMOS, CONFLICTOS E INSTRUMENTALIZACIONES. INTANGIBLE CULTURAL HERITAGE: REDUCTIONISMS, CONFLICTS AND INSTUMENTALIZATIONS. MARZO DE 2017

ISSN 2174-6796

[pp. 1-30]

http://dx.doi.org/10.12795/RAA.2017.12.01

\title{
PATRIMONIO INMATERIAL: REDUCCIONISMOS, INSTRUMENTALIZACIONES POLÍTICO Y ECONÓMICAS Y CONFLICTOS DE APROPIACIÓN SIMBÓLICA
}

\section{INMATERIAL CULTURAL HERITAGE: REDUCTIONIS, POLITICAL AND ECONOMIC INSTRUMENTATIONS AND SYMBOLIC APPROPRIATION CONFLICTS}

\author{
Gema Carrera Díaz \\ Instituto Andaluz del Patrimonio Histórico \\ Miembro del grupo GEISA \\ Miembro del Proyecto PARTICIPAT
}

\section{Resumen.}

Este artículo introduce las problemáticas tratadas por las distintas aportaciones de este monográfico sobre las instrumentalizaciones que se están produciendo en torno al "patrimonio cultural inmaterial" (PCI) a partir de la Convención de UNESCO de 2003. La importancia teórica que se otorga a las "identidades culturales", la "participación social", la "diversidad cultural” y las "comunidades" se aleja mucho de las prácticas y patrimonializaciones reduccionistas realizadas a partir de la aplicación de este concepto. Algunas de estas patrimonializaciones ocultan bajo los valores antes mencionados objetivos de tipo económico, turístico, político y electoralista, poniendo así en peligro las potencialidades del concepto de PCI para transformar la sociedad y frenar o amortiguar los efectos de la globalización y la homogeneización que esta comporta.

Palabras claves:

Patrimonio Cultural Inmaterial, UNESCO, patrimonialización, mercantilización, conocimientos tradicionales. 


\begin{abstract}
.
This article introduces the issues dealt with by the different contributions of this monograph on the use of the "Intangible Cultural Heritage" (CIP) in the context of the UNESCO Convention of 2003. The theoretical importance given to "Cultural"”, social participation", "cultural diversity" and "communities" is far from the reductionist practices and heritagizations made from the application of this concept. Some of these heritagizations hide under the aforementioned values, economic, tourist, political and electoral objectives, thus jeopardizing the potential of the concept of CIP to transform society and to curborcushion the effects of globalization and the homogenization that this entails.
\end{abstract}

\title{
Keywords:
}

Intangible Cultural Heritage, UNESCO, heritazation, traditional knowledge.

\section{INTRODUCCIÓN}

La Convención para la Salvaguarda del Patrimonio Cultural Inmaterial (UNESCO, París, 2003) ha intensificado la proliferación de "patrimonializaciones" en torno a elementos culturales desde una lógica predominantemente identitaria y referencial permitiendo, a partir de procesos de apropiación diversos, la visibilización de determinados grupos sociales antes silenciados. Se trataría, teóricamente, de procesos de patrimonialización participados por parte de una comunidad heterogénea formulados en torno a reivindicaciones culturales o ambientales para la defensa de determinados elementos culturales que sienten amenazados o con los que se sienten identificados.

Pero, al mismo tiempo, el impacto social de las listas de UNESCO de patrimonio inmaterial, su “inflación patrimonial” (Heinich, 2009) y su expansión sin límites han generado una serie de contradicciones en torno a estos procesos de patrimonialización que producen paradójicamente los efectos contrarios que pretende la Convención.

El "Discurso Autorizado de Patrimonio" (Smith, 2006) comienza a emplear de forma cosmética o instrumental los conceptos de diversidad cultural, identidad, comunidad o participación social en torno al patrimonio inmaterial, que se convierten en objeto de activaciones realizadas de forma no integrada por agentes de diverso tipo (políticos, empresariales, etc.) con objetivos más relacionados con el aprovechamiento 
económico, empresarial, turístico, político y electoralista de estos nuevos “artefactos metaculturales" (Kirshenblatt-Gimblett, 2004) alejados del sentido dado al PCI por parte de la Convención.

La UNESCO, con la Convención del Patrimonio Inmaterial (2003), después de 30 años de la Convención del Patrimonio Mundial (1972), reflexionando sobre el eurocentrismo y el desequilibrio global presente en su primera Lista, con documentos generados en esta trayectoria que reflejan los cambios en las políticas culturales de todo el planeta, nos aporta una reformulación total del concepto de Salvaguarda y aboga por una gestión del patrimonio mucho más participativa, centrada en las "comunidades" y sus conocimientos. Sin embargo, deja sin protección y en manos de la OMPI e intereses particulares las cuestiones mucho más lucrativas, relacionadas con la protección de la propiedad intelectual y los conocimientos tradicionales. Por otro lado, UNESCO con esta nueva convención vuelve a crear de manera vaga la dicotomía ya superada de patrimonio material-inmaterial (Bouchenaki, 2003) nada positiva para una gestión holística e integradora del patrimonio. Además, instaura el sistema de Listas independientes de la otra convención, intentando con esto aumentar la representación de la diversidad cultural del planeta como resultado de su "Estrategia Global" (UNESCO, 1994) y de los países menos representados en la lista de la Convención del Patrimonio Mundial (1972). Pero con ello, ¿qué ha conseguido? ¿Es quizás una respuesta camuflada en un bonito discurso por la “maquinaria patrimonial” (Alonso González, 2013) a la demanda de lo 'auténtico’ y exótico en el mercado? (Santamarina, 2011).

Este monográfico, denominado "Patrimonio Inmaterial, reduccionismos, conflictos e instrumentalizaciones", analizará desde la antropología y con diversas perspectivas (ya sea desde el ámbito académico como desde la gestión patrimonial) este tipo de situaciones.

\section{ELPAPEL DELA ANTROPOLOGÍAENLA DETECCIÓNDEREUCCIONISMOS Y SIMPLIFICACIONES EN TORNO AL PATRIMONIO CULTURAL}

La incorporación de la antropología al ámbito del patrimonio cultural ha supuesto, entre otras cosas, su definición como construcción social. Es decir, el patrimonio cultural constituye una selección de rasgos de una cultura determinada que uno o varios grupos realizan con diversas finalidades como resultado de un proceso social o “patrimonialización” (Ariño Villarroya, 2002; Fernández de Paz y Agudo, 1999; Amougou, 2004). 
Podríamos afirmar que no existen elementos intrínsecamente patrimoniales sino procesos de patrimonialización y actores que patrimonializan con visiones más o menos amplias o reducidas. Para cada elemento patrimonializado (Ej.: el flamenco, la dieta mediterránea, la Fiesta de los patios de Córdoba o su mezquita catedral, las Fallas de Valencia, la Semana Santa o la fiesta de los toros, o el Conjunto arqueológico de los Dólmenes de Antequera, un parque natural o un tipo de cultivo...) es importante comprender quiénes son los actores que intervienen, qué objetivos persiguen, qué contenidos y qué comunidad de referencia invocan (Quintero, 2009). Desde esta perspectiva, y como afirma Santamarina en este monográfico, el patrimonio cultural es una categoría política donde se producen conflictos ideológicos y sociales. Entran en discusión intereses de partido, intereses económicos o reivindicaciones identitarias o ambientales y presiones locales (Quintero, 2009; Sánchez Carretero, 2012).

La presencia de activaciones patrimoniales desde una lógica identitaria y referencial se hizo más evidente a partir de la ampliación del concepto de patrimonio cultural, especialmente en los años noventa (Agudo, 1999; Padiglione, 1999) con la incorporación del enfoque antropológico o del patrimonio cultural inmaterial -en adelante, PCI-, fundamentalmente a partir de la Convención para la Salvaguarda del Patrimonio Cultural Inmaterial (UNESCO, París, 2003). Se abría así una nueva etapa prometedora que ampliaba los nosotros colectivos representados por el patrimonio. Ello ha permitido, a partir de procesos de apropiación diversos, la visibilización de determinados grupos sociales antes silenciados y no representados. Se trata de procesos de patrimonialización participados por parte de una comunidad heterogénea formulados en torno a reivindicaciones culturales o ambientales para la defensa de determinados elementos culturales que sienten amenazados o con los que se sienten identificados (Carrera, 2016). Ello se debe, en parte, a la dialéctica contemporánea que se produce entre globalización-localización o territorializacióndesterritorialización, en la que determinados procesos de patrimonialización pueden convertirse en proyectos societarios alternativos tanto en el plano económico como en el social, ambiental, político y simbólico para algunos actores, siendo un ejemplo positivo de cómo los procesos de patrimonialización de la cultura pueden frenar o amortiguar los efectos de la globalización y la homogeneización que esta comporta (Moreno Navarro, 2002: 137). Sin embargo, esta capacidad de resistencia del patrimonio inmaterial para determinados grupos sociales subalternos, pronto se ve truncada por nuevos intereses y estructuras de poder que se empeñan en explotar su potencial rentabilidad económica y política y amortiguar su capacidad 
de transformación social y, para ello, usan de forma cosmética o instrumental los conceptos de diversidad cultural, identidad, comunidad o participación social en torno al patrimonio inmaterial. Para muchos agentes esta patrimonialización constituye un recurso al servicio de sus intereses políticos y económicos. Para abordar más en profundidad esta problemática, este monográfico ha reunido autoras que, desde la antropología y desde sus diferentes ámbitos territoriales y profesionales, analizan diferentes procesos de patrimonialización donde conviven actores de tipo institucional, político, del ámbito privado o empresarial, de la sociedad civil y miembros de las comunidades o grupos directamente relacionados con el elemento patrimonializado.

Contamos, para ello, con visiones de antropólogas que trabajan en el ámbito de las políticas culturales y administraciones competentes en la gestión patrimonial en diferentes ámbitos político-territoriales (Cécile Duvelle en el internacional; en el ámbito del Estado brasileño, Monia Silvestrin y Diana Dianovosky del Instituto do Patrimônio Histórico e Artístico Nacional de Brasil (IPHAN); en el plano autonómico dentro del Estado español, Fuensanta Plata del servicio de protección del patrimonio Histórico; o quien escribe estas líneas, del Instituto Andaluz del Patrimonio Histórico, ambas entidades de la Consejería de Cultura de la Junta de Andalucía). Asimismo, se suman las aportaciones realizadas a partir de estudios e investigaciones antropológicas de diversos procesos de patrimonialización relacionados con el patrimonio inmaterial (Cristina Sánchez-Carretero del IncipitCSIC; Victoria Quintero Morón de la Universidad Pablo de Olavide; Beatriz Santamarina Campos de la Universidad de Valencia; y, por último, Chiara Bortolotto del Institut interdisciplinaire d’anthropologie du contemporain de París).

Una de las claves del análisis de las contradicciones y paradojas que introduce la Convención para la Salvaguardia del Patrimonio Cultural Inmaterial de 2003 es el uso de la participación social y de la expresión "comunidades, grupos y en algunos casos individuos" como principal innovación de este texto. La distancia entre el discurso, los métodos y su aplicación resulta más que evidente como pondrán de relieve Cristina Sánchez-Carretero y Victoria Quintero Morón. Su artículo se centra en las contradicciones que se dan entre los discursos (verbos) y prácticas (conjugaciones) en torno a la participación en el caso del patrimonio inmaterial. Temática crucial y transversal en todas las aportaciones de este monográfico.

En el ámbito internacional, Cècile Duvelle, jefa de la Sección de Patrimonio Inmaterial de la UNESCO y Secretaria de la Convención para la Salvaguardia del Patrimonio 
Cultural Inmaterial de 2008 a 2015, ha protagonizado el proceso de elaboración y negociación de varios instrumentos normativos, particularmente la Convención de 2003. La autora, en la medida en que le es posible, analiza críticamente los conflictos de intereses que se producen en el seno de los "estados partes" de la Convención y en los procesos de candidatura e inscripción en las listas muchas veces alejadas de los principios de este instrumento normativo que ha pretendido renovar el discurso patrimonial poniendo el foco sobre las "comunidades, grupos e individuos", al tiempo que son los estados partes quienes acaparan la gestión y están legitimados para ello.

Mônia Silvestrin y Diana Dianovsky, antropólogas del departamento del patrimonio inmaterial del IPHAN, analizan varios procesos de patrimonialización y sus relaciones con las dimensiones políticas y de mercado: el caso da Arte Kusiwa, Pintura corporal y arte Gráfica Wajãpi y el del oficio de la producción artesanal y comercio ambulante de las comidas llamadas "de baiana" de Acarajé vinculadas al culto afrobrasileño de los orishas del candomblé.

Fuensanta Plata, jefa del departamento de catalogación del Patrimonio Histórico de la Consejería de Cultura esboza un conflicto de apropiación en torno al patrimonio inmaterial en el ámbito político-administrativo, estatal y autonómico, a partir de la promulgación de la Ley para la salvaguardia del Patrimonio Cultural Inmaterial de 2015 del Estado. Así mismo, la autora reflexiona acerca del contenido, complejidad y significados del patrimonio cultural andaluz haciendo hincapié en las actividades de interés etnológico actualmente inscritas en el Catálogo General del Patrimonio Histórico Andaluz.

Beatriz Santamarina, empleando una metáfora muy fallera, aborda el fenómeno de la "explosión" de lo inmaterial en el marco de la políticas internacionales y en el contexto del tercer espíritu del capitalismo y realiza un análisis crítico de las activaciones patrimoniales de los bienes inmateriales en el País Valenciano con objetivos políticos, económicos o identitarios por diversos actores patrimoniales.

Por último, Chiara Bortolotto centra su análisis en una temática muy concreta e ilustrativa de las instrumentalizaciones económicas que este monográfico ha puesto sobre la mesa: el patrimonio cultural inmaterial alimentario en el marco de la Convención de la UNESCO, enfocando la fricción entre los principios y objetivos de la Convención y las expectativas iniciales de los proyectos de patrimonialización en la esfera alimentaria. Nada que no pueda solucionarse gracias al poder performativo del "discurso patrimonial autorizado" (Smith, 2006), en este caso a través de las directrices operativas elaboradas por la UNESCO, que eficazmente empleadas 
servirán para adecentar las candidaturas internacionales en este ámbito y disimular a través del discurso, el uso neoliberal de la cultura como un recurso.

Desde mi punto de vista algunos de los problemas que se producen en el ámbito de la gestión relacionados con el patrimonio cultural en general y el PCI en particular, y que este número de la RAA pretende poner de relieve, se derivan de posiciones reduccionistas de diferente tipo relacionadas con el concepto de patrimonio inmaterial: materialistas-objetuales, esencialistas-inmateriales y mercantilistasinstrumentales.

\section{EL REDUCCIONISMO OBJETUAL-MATERIAL DEL PATRIMONIO INMATERIAL}

En el "Discurso Autorizado de Patrimonio"(Smith, 2006), sus agentes legitimados (técnicos-expertos, académicos), instrumentos legales, políticas relacionadas con la protección del patrimonio cultural, herramientas y técnicas creadas para su documentación, impera aún una visión vertical de la gestión, con una visión experta, monumental, material, singular, estética y un concepto de protección adaptado a estos valores. Las instituciones implicadas y legitimadas hasta el momento para la gestión o protección del patrimonio suelen considerar a la sociedad como una mera receptora de productos culturales acabados (un bien catalogado, un bien documentado, una ruta cultural, ...). La protección, en la mayor parte de los casos, se sigue relacionando con una idea de custodia, mantenimiento y conservación perenne de objetos o actividades que deben transmitirse intactos a las nuevas generaciones, imperando en los procesos de decisiones e instrucciones para la salvaguarda las perspectivas técnico-expertas sin apenas alguna participación social en las mismas.

Una de las medidas más recurrentes en la documentación y protección de este patrimonio, heredado de un concepto de patrimonio relacionado con los objetos, es la materialización o fijación en soportes materiales de las actividades y expresiones vivas (registros documentales, sonoros o audiovisuales). Otra de ellas, por muy vivo y vigente que sea un elemento cultural, es su museificación (museos de identidades, museos de pesca, museos de la fiesta, museos de los patios, museo de la cal...). Ello ha conducido a quienes trabajan en las administraciones competentes en materia de protección de patrimonio cultural a diseñar fórmulas de protección indirectas, más bien adaptadas a objetos muebles e inmuebles que a actividades, procesos o manifestaciones vivas de la cultura. 
En otras ocasiones, se tiende a no operar directamente (Lacarrieu, 2008). En Andalucía, a pesar de que desde hace más de 24 años existe la facultad administrativa para "proteger" estos elementos culturales como actividades de interés etnológico (Ley 1/1991 de PHA), las acciones de protección directa han sido excasas. Cuando han existido, dada las grandes dificultades que ello supone (Plata y Rioja, 2005; Rioja, 1996, 2006) no han sido suficientemente eficaces para garantizar la continuidad de la actividad a pesar de la voluntad y esfuerzo de sus protagonistas y de los expertostécnicos implicados. En este sentido, aunque la primera ley andaluza de patrimonio histórico fue pionera en el Estado por otorgar un tratamiento integrador y holístico al patrimonio cultural y al valor identitario a través de la importancia otorgada al patrimonio etnológico, la segunda, o Ley 14/2007 de Patrimonio Histórico de Andalucía, no reflejaba los avances que en materia de salvaguarda aportaba la convención (artículos 11,12,13,14, y 15) a pesar de que ésta ya había sido ratificada por el Estado español en 2006.

Una de las medidas que favorece la vigente ley andaluza para proteger una "actividad de interés etnológico" y que se presenta como gran avance de la misma, es la protección de los ámbitos territoriales, espacios o inmuebles asociados afectados por una actividad ritual o productiva (más materiales o asibles que el proceso o actividad en sí).

Es decir, asistimos a un ejemplo de protección "indirecta” a través de una visión material-objetual de la protección, que aunque necesaria en algunos casos concretos, es una medida incompleta y muy alejada de la necesaria participación social, de la vertiente procesual de este patrimonio y de la necesidad de concertación y acuerdo con otras políticas sectoriales.

En el caso concreto de los oficios tradicionales o artesanales, la mayor parte de las medidas realizadas por la Consejería de Cultura, como describe Rioja (2006), también están relacionadas con medidas indirectas sobre los mismos a través de la protección de los objetos (muebles o inmuebles) relacionados con los oficios artesanos extintos o en vías de desaparecer como son las realizadas a partir de la musealización de bienes muebles o a partir de la protección administrativa de bienes muebles e inmueble.

Una forma indirecta de protección ha sido la inscribir bienes inmuebles o colecciones de bienes muebles ubicados en el mismo (Colección Histórica de la fábrica La Cartuja de Sevilla y su archivo histórico; los bienes muebles de la Fábrica de vidrios 
La Trinidad de Sevilla; o los bienes muebles de las caleras de la Sierra de Morón de la Frontera) (Rioja, 2006).

Hay elementos culturales cuya patrimonialización podría estar dirigida a contrarrestar, mediante la concertación y acuerdo previo, las acciones emprendidas por otras instancias que dificultan la continuidad de estas actividades debido a la aplicación de normativas sectoriales que no tienen en cuenta su impacto sobre estos elementos culturales por atender solo a su vertiente económica o a la de su competencia en cuestión.

Un ejemplo de ello es la prohibición de usos sociales en espacios protegidos, como son la recolección de hierbas aromáticas, de frutos silvestres, la tala, la poda, la extracción de materias primas con escaso impacto ambiental como la piedra caliza para hornos tradicionales, el esparto, la leña, la pizarra para la construcción de muros de piedra seca y su aplicación a los cultivos en terraza... Así como la prohibición de actividades productivas tradicionales (como la pesca fluvial, la pesca marítima artesanal,... a favor de otras actividades más intensivas, tanto extractivas como de acuicultura); o la prohibición del uso de la leche cruda o el cuajo natural para la elaboración de quesos artesanales, obligando a la venta de leche de alta calidad a otras zonas productoras de queso, relegando la actividad ganadera a actividades primarias y no de transformación; la prohibición de matanzas domésticas a favor de la producción industrial de productos cárnicos; o la obligación de estabular al ganado eliminando los sistemas de explotación extensivos, adehesados; la eliminación de medidas de fomento agrícola a la pequeña propiedad y a cultivos tradicionales o en pendientes en favor de la gran propiedad agrícola, latifundista y de campiña, o de formas de explotación intensivas, más rentables económicamente pero menos sostenibles medioambiental y socialmente hablando (como los cultivos transgénicos o la agricultura intensiva bajo plástico). Todas estas normativas y líneas de actuación política afectan a la continuidad de actividades que podríamos considerar patrimonio inmaterial. Es decir, muy pocas veces se ponen en marcha medidas omnicomprensivas que impliquen la coordinación intersectorial entre administraciones públicas (costas, medio ambiente, artesanía, educación) y de todas estas con la sociedad, haciendo mucho más participativas las decisiones que puedan implicar modificaciones profundas en los modos de vida y de trabajo de muchos colectivos, en los ecosistemas en los que estos se desarrollan y en sus culturas del trabajo. Imperan, por tanto, los enfoques conceptuales más objetuales por encima de otros de carácter más holísticos e integradores que acentúen los valores simbólicos 
e identitarios y el carácter dinámico y procesual de todo patrimonio ${ }^{1}$. Las pocas iniciativas para proteger este tipo de patrimonio cultural por parte de los catálogos estatales o autonómicos, sobre todo en Andalucía, vienen promovidos y auspiciados por la sociedad civil en el momento en el que encuentran dificultades para salvaguardarlas por sí mismos y llegan a lograr la necesaria concertación entre la administración y la sociedad civil (Ej: corrales de pesca de la costa noroeste andaluza). Muchas veces, por el contrario, es la propia labor normativa del Estado (en sus escalas europea, española y autonómica), la que impide que los colectivos sociales puedan seguir recurriendo a los métodos tradicionales de transmisión y continuidad de actividades que de este modo han sido históricamente sostenibles, haciendo imperar el conocimiento científico-técnico-burocrático sobre el conocimiento tradicional.

\section{LA ESENCIALIZACIÓN DE LO “INMATERIAL". EL CASO DE LA LEY 10/ 2015 PARA LA SALVAGUARDIA DEL PATIRMONIO CULTURAL INMATERIAL}

$\mathrm{Al}$ mismo tiempo que se tiende a materializar los elementos culturales inmateriales como medida más recurrente en la protección de los mismos, se realiza también la operación justamente contraria: intangibilizar y deslocalizar para instrumentalizar con más facilidad este patrimonio cultural y su apropiación simbólica. Y es que, efectivamente, el patrimonio cultural inmaterial, esencializado y deslocalizado, puede ser un instrumento muy eficaz de poder.

En el estado español, la reciente Ley 10/2015 de 26 de mayo para la salvaguardia del Patrimonio Cultural Inmaterial es un ejemplo evidente de cómo en el ámbito político-legislativo se emplea de forma cosmética o instrumental los conceptos de "diversidad cultural", "identidad", "comunidad" o "participación social" en torno al patrimonio inmaterial contrarrestando su capacidad transformadora por parte de agentes colectivos como movimientos sociales de distinto tipo (Hernández Ramírez, 2004), o bien, anteponiendo y justificando la consolidación de tradiciones culturales que no representan la diversidad cultural de un Estado, sino aquellas que pueden servir para lo contrario: homogeneizar y crear una identidad "nacional-Estatal". Sin embargo, ninguna comunidad autónoma ha recurrido la ley, y el debate político

1. Este problema se ha intentado evitar en el Atlas del Patrimonio Inmaterial de Andalucía realizado por la Consejería de Cultura a través del IAPH con una metodología antropológica y participativa y una visión integradora del patrimonio cultural. Este proyecto surge en Andalucía y se ha convertido en un modelo de gestión del patrimonio inmaterial a nivel regional, estatal e internacional (Carrera, 2009, 2016) 
parece haberse concentrado solo sobre el problema de la tauromaquia ${ }^{2}$, que ha desviado, estratégicamente, gran parte de la atención de los demás partidos políticos dada la atención mediática prestada al asunto de la prohibición de la fiesta de los toros en Calalunya. Ello ha hecho perder de vista asuntos de crucial importancia. Esta ley resulta ser un instrumento para blindar la protección de determinados elementos culturales de sospechoso carácter "nacional-españolista" convirtiendo su prohibición en algo anticonstitucional como se ha hecho recientemente en Catalunya ${ }^{3}$, que tampoco recurrió la ley estatal de patrimonio inmaterial en su momento. Más allá de los intereses de partido asociados a la defensa o prohibición de la fiesta de los toros, esta ley se basa estratégicamente en un reduccionismo muy habitual y en este caso muy rentable políticamente: el "esencialista-inmaterial" aplicable a muchos más elementos culturales y que el gobierno estatal está empleando con intereses centralistas, electoralistas y mercantilistas generando un término tan economicista como homogeneizador para denominar a una idea mixtificada de la cultura a nivel de estado : la "marca España".

La ley elude, cuando es conveniente, la relación entre lo material y lo inmaterial inherente a estas expresiones culturales. Todo el proyecto de ley se construye en base a una lectura errónea del calificativo "inmaterial" muy funcional a esta intención de deslocalización de lo "inmaterial", algo que por otra parte, este calificativo ha facilitado. El texto no entiende "inmaterial" en su sentido procesual sino en un sentido de intangibilidad, de falta de materia. Esta ausencia de "locus" le permite emplear de manera burda la doctrina de la "supraterritorialidad".

"Su objetivo, según señaló, es proteger patrimonio que carece de una base material pero es "importante" por la diversidad cultural, citando a las tradiciones, rituales,

2. Entrelas disposiciones finales, la sexta hace referencia a la regulación de la tauromaquia como patrimonio cultural (el gran bastión cultural que ha defendido el PP en su última legislatura ante la iniciativa catalana de prohibir las corridas de toros). Este constituye un indicador obvio de la instrumentalización de este patrimonio para la lucha política en relación a la construcción de las identidades. "Lo establecido en la presente Ley se entiende, en todo caso, sin perjuicio de las previsiones contenidas en la Ley 18/2013, de 12 de noviembre, para la regulación de la Tauromaquia como patrimonio cultural" (Disposición final sexta del Ley 10/2015).

3. El TC afirma que la competencia de la Generalitat en materia de espectáculos públicos no incluye prohibir las corridas de toros, declaradas por ley patrimonio cultural inmaterial. "El Pleno del Tribunal Constitucional ha estimado el recurso de inconstitucionalidad presentado por el Grupo Parlamentario Popular en el Senado y ha declarado inconstitucional y nulo el art. 1 de la Ley 28/2010 que prohíbe la celebración de corridas de toros y otros espectáculos taurinos en Cataluña. (TRIBUNAL CONSTITUCIONAL. Gabinete del Presidente Oficina de Prensa. NOTA INFORMATIVA No 85 12016)" Consultado en https://es.scribd.com/document/328304259/Nota-Informativa-del-TC-ElConstitucional-anula-la-ley-catalana-que-prohibe-la-corrida-de-toros\#from_embed (20 de febrero de 2017) 
actos festivos, saberes y prácticas vinculadas a tradición artesanal." (Declaraciones del entonces ministro de cultura durante la presentación en el Congreso en diciembre, Europa Press, 14/05/2015).

Según la ley podrán ser declaradas como Manifestaciones Representativas del Patrimonio Cultural Inmaterial (MRPCI) los elementos culturales del PCI que sean comunes en distintos territorios del Estado, "cuando superen el ámbito territorial de una Comunidad Autónoma y no exista un instrumento jurídico de cooperación entre Comunidades Autónomas para la protección integral de este bien" (art 12.1.a.), afirmando que no se incumple la sentencia 17/1991 del Tribunal Supremo ${ }^{4}$ para el caso del PCI y que por tanto el Estado puede tener competencias en el mismo.

El Estado para declarar MRPCI realiza generalizaciones a escala estatal de prácticas culturales que comparten algunas características formales o de temporalidad (como el repentismo, la Semana Santa, Los Moros y Cristianos) $)^{5}$. Se pretende así cumplir el supuesto recogido en el artículo 12.1.c) "Cuando la consideración en conjunto del bien objeto de salvaguardia requiera para su específica comprensión una consideración unitaria de esa tradición compartida, más allá de la propia que pueda recibir en una o varias Comunidades Autónomas". Esto es algo bastante improbable, y si se considera necesaria una protección jurídica unificada del bien esta podría realizarse mediante una Ley armonizadora que no es el caso de esta Ley. Las competencias autonómicas en patrimonio cultural no están reñidas con que las CC.AA. puedan asumir de forma coordinada la salvaguarda del PCI siempre que su población lo considere como parte de su patrimonio cultural y siempre que les infunda un sentimiento de identidad y pertenencia y convengan en practicar medidas conjuntas.

Por el contrario, y de manera deslabazada, a lo largo de la LPCIE se hace también alusión a las medidas indirectas de salvaguarda mediante la protección de elementos materiales (muebles o inmuebles) (art.4). Con ello, de manera igualmente indirecta,

4. La declaración de una "Manifestación Representativa del Patrimonio Cultural Inmaterial" (MRPCI) supone un cambio cualitativo con relación al modelo impuesto por la sentencia constitucional 17/1991, de 31 de enero, que retiró casi por completo la atribución de efectuar declaraciones a la Administración General del Estado. Sin embargo, en la Ley 10/2015 se intenta invalidar esta sentencia para el caso del PCI.

5. Esto mismo podría hacerse con el Patrimonio Cultural inmueble entre las catedrales góticas o iglesias románicas o palacios renacentistas de toda España, pero ello no implica una deslocalización del inmueble como tampoco debería implicar una deslocalización de la práctica concreta, que es única para la comunidad que la practica y que se siente representada por ella. El hecho de que haya inmuebles representativos de un mismo estilo arquitectónico o periodo histórico no posibilita al Estado el realizar una declaración unitaria de los mismos. 
el Estado se otorga, ahora sí materializando lo que antes era intangible, competencias sobre los bienes muebles e inmuebles localizados en los territorios de las CC.AA. y además de una manera un tanto basta, esta materialización le permite poder introducir un artículo sobre "Expoliación y Exportación de bienes muebles", casualmente la única competencia que tiene el Estado en materia de Patrimonio Cultural (art. 5.1 de la Ley 10/2015).

Esta instrumentalización de la Convención y la interpretación errónea del patrimonio "inmaterial" como carente de base material es altamente inapropiada y se aprovecha para deslocalizar o esencializar y, así, atribuirse competencias sobre los aspectos más "españolizados" y "españolizables" de las diferentes regiones del Estado. Aunque quizás, todo el discurso de la Convención sea realmente funcional a estas estrategias de los Estados centralistas que no reconocen su diversidad interna, ya que son los Estados los mediadores entre las "comunidades" y la patrimonializadora global: "UNESCO". La homogeneización cultural a través de este patrimonio y el uso de las instituciones gubernamentales para su patrimonialización (en el seno del parlamento, cortes, senado por parte de grupos parlamentarios) parece ser una tendencia actual en el Estado español. En este sentido no deja de ser llamativo que sean partidos políticos quienes inicien solicitudes para declaraciones patrimoniales en las instituciones, motu proprio y sin responder a reclamaciones de colectivos sociales. Este modvs operandi no solo anula el papel primordial que deben tener las comunidades, grupos e individuos que protagonizan los diferentes elementos del PCI, sino que además desestima cuantas competencias sobre patrimonio cultural tienen las respectivas CC.AA. que conforman el Estado (entre ellas, la andaluza como señala Fuensanta Plata en su artículo). En definitiva, ya sea a través de la declaración de la tauromaquia, la semana santa o el carnaval, la cultura del esparto, o la tapa de España, esta ley es una forma de instrumentalizar políticamente las identidades culturales, homogeneizándolas, desvitalizándolas y mercantilizándolas, utilizando el "patrimonio inmaterial" como coartada, aludiendo de manera nuevamente cosmética a un discurso (el de la Convención UNESCO).

\section{LA MERCANTILIZACIÓN Y TURISTIZACIÓN DEL PATRIMONIO INMATERIAL}

Al mismo tiempo y relacionado con lo anterior, persiste un reduccionismo instrumental -economicista en el tratamiento del patrimonio cultural y, en concreto, del inmaterial. La preocupación por los valores culturales de estos elementos no 
parece tener coherencia con las verdaderas intenciones de explotación turística y económica de la mismos como ya ocurre desde hace tiempo con otros elementos patrmonializados (Hewison, 1987).

"De las muchas cosas buenas que tiene España la tapa es una de ellas. La idea de preservar la tapa como un valor propio, uno de los signos distintivos de la marca España, es algo en lo que estamos todos los españoles de acuerdo, por eso hemos decidido impulsar la tapa como Patrimonio Inmaterial Español. Después de terminado este proceso, pensamos elevarlo también a la UNESCO para que se considere Patrimonio de la Humanidad." (declaraciones del Ministro en funciones, Íñigo Méndez de Vigo en la nota de prensa del Ministerio de Educación, Cultura y Deportes, 16 de junio de 2016).

La instrumentalización económica que se hace de estos bienes por parte de diversos agentes es también una cuestión preocupante. ¿Cómo instrumentalizan los diversos agentes, incluidos la pretendida "comunidad", estratégicamente indefinida, vaciada de significado, esta apropiación de los bienes y conocimientos que heredan y transmiten, siendo las dinámicas de creación cultural continua y libre, y estando muchas veces relacionadas con el préstamo cultural y con la hibridación? (Hafstein, 2011). En el mismo sentido, proliferan nuevos conceptos creados o generados en torno a la mercantilización de la cultura en su acepción humanística, "Industria cultural", "turismo cultural", industrias creativas" y "economía de la cultura" (Adorno y M. Horkheimer, 1998; Pérez, 2006).

En el ámbito del turismo, progresivamente, diversos elementos de la cultura en sentido antropológico se incluyen en el mercado de la "industria turística cultural” o del "turismo rural". Estos se convierten en "recursos" de las propuestas para el turismo cultural de las zonas rurales, desagrarizadas, en parte, por las políticas agrarias globales (Política Agraria Comunitaria-PAC-). Se patrimonializan con tal fin las formas de vida, formas de producir y trabajar, fiestas, música, danzas tradicionales y formas de alimentarnos, entendidos por quienes lo explotan económicamente, como recursos económicos que centrarán las políticas y estrategias turísticas, culturales, medioambientales.

El avance de la globalización mercantilista y la conversión de la cultura y el patrimonio cultural en un recurso económico es cada vez más importante en las ofertas turísticas. El patrimonio etnológico y especialmente el PCI están sujetos a las inexorables leyes del mercado. La cultura tradicional es demandada por un turismo cada vez más diversificado y reorientado hacia otros destinos temáticos y territoriales (Cohen, 
2001; Agudo, 2005; Greenwood, 1997); ahora bien, este también puede ser empleado sin reduccionismo y con resposanbilidad otorgando mayor capacidad de adaptación y resiliencia (Gascón , 2009; Escalera, 2011). Actualmente, como afirma Juan Agudo se da una situación paradójica en torno a este patrimonio cultural:

"significativamente, buena parte de los elementos culturales que se instrumentalizan más directamente en los discursos político-culturalistas étnicos van estar extraídos de los contenidos de lo que denominamos patrimonio etnológico. Y sin embargo, en una aparente paradoja que no lo es tal de acuerdo con la propia lógica del mundo en que vivimos, también asistimos a una reinterpretación de este patrimonio etnológico en clave de mercado, en el que las propias "identidades" se han convertido en un recurso más al asociarse a unos particularismos-autenticidades que son crecientemente demandas/ofertadas en un mercado turísticos en el que el patrimonio es visto como un recurso que ha de adaptarse a esta demanda." (Agudo Torrico, 2005: 197)

Sin lugar a dudas, la mercantilización, espectacularización o turistización y uso político de los bienes culturales, incluyendo a una velocidad vertiginosa al denominado "patrimonio cultural inmaterial", es uno de los fenómenos actuales que más afectan a la cultura y al patrimonio cultural. La defensa de los bienes culturales como bienes colectivos y referenciales convive en los últimos años con una aceptación por parte de algunos agentes de la lógica de la globalización desde cualquier ámbito, privatizándose incluso de forma individual lo que pertenece a un colectivo o mercantilizándose expresiones culturales y vaciándolas de contenido. El patrimonio inmaterial es empleado por agentes, muchas veces de carácter privadopúblico, que persiguen objetivos relacionados con el aprovechamiento económico, empresarial y turístico, convirtiendo a estos elementos culturales en "artefactos metaculturales" (Kirshenblatt-Gimblett, 2004, 56) que hacen más amplio, provechoso, variado y rentable el negocio patrimonial, sin la necesidades de inversión que comporta el deterioro de los bienes muebles e inmuebles para las instituciones ${ }^{6}$. Este reduccionismo instrumental parte de una visión de desarrollo igualmente limitada al mero crecimiento económico como si cultura y economía fuesen cosas separadas.

6. Serán fundamentales, en este sentido, las aportaciones de Chiara Bortolotto sobre el patrimonio alimentario en las listas de UNESCO o los casos presentados por nuestras colaboradoras brasileñas del IPHAN, Mônia Silvestrin y Diana Dianovsky. Como destacan todas las autoras, desde la propia Cécile Duvelle, las listas de UNESCO de patrimonio inmaterial, entre otras, han generado una serie de contradicciones en torno a estos procesos de patrimonialización que producen paradójicamente los objetivos contrarios que pretendía la Convención. 


\subsection{EL USO TURÍSTICO DEL PATRIMONIO INMATERIAL. EL CASO DE LA FIESTA DE LOS PATIO DE CÓRDOBA}

En este sentido, podemos destacar la mediática y doble candidatura a la Lista representativa del PCI de UNESCO de La Fiesta de losPatios de Córdoba. La primera, en 2011, denotaba la componente objetual de los procesos de patrimonialización (su reduccionismo material-objetual) en torno a este patrimonio y la incomprensión en cuanto al nuevo concepto de salvaguarda propuesto por la Convención. La segunda en 2012, tras la presión política local al respecto, fue modificada por la CC.AA. y defendida con éxito por el Estado en el Comité intergubernamental, cumpliendo formalmente con los principios de la Convención y adaptándose correctamente al nuevo "Discurso Autorizado de Patrimonio" impuesto por las directrices operativas de la Convención (algo que Chiara Bortolotto analizará en est monográfico para el caso de las candidaturas relacionadas con el patrimonio alimentario a las Listas de UNESCO).

No obstante, pronto sería más que evidente el objetivo latente de esta candidatura, liderada por el ayuntamiento de Córdoba, para el que los patios y su fiesta se han convertido en uno de los ejes vertebradores de la política turística de la ciudad. Su transfiguración mediante la candidatura en un patrimonio "global" ha servido para convertirlo en un recurso económico más funcional a la política local y a uno de sus máximos beneficiarios: las empresas turísticas y la hostelería cordobesa (lejos de ser los "portadores" o comunidad protagonista tal y como la concibe la UNESCO: es decir, los propietarios de patios o la población que va de patios). Esta candidatura, como muchas otras, demuestra que asistimos a una mercantilización de lo simbólico sin precedentes. Los elementos culturales, en este caso la fiesta de los patios de Córdoba y los patios en sí, se convierten en una producción cultural impulsada por determinadas instancias políticas o empresariales, o incluso por algunos propietarios, no por su valor de uso sino por su valor de cambio en el mercado.

"El alcalde de Córdoba subraya que la capital tiene "un buen producto y están llegando los resultados" tras la gestión realizada, algo a lo que se suma el convenio de colaboración con la Unesco, aprobado este viernes en Junta de Gobierno Local, con unos 22.500 euros para "la mejora de la promoción, difusión y salvaguarda de la fiesta de los patios", como ha señalado la edil de Fiestas y Tradiciones Populares." [el subrayado es nuestro] (Europa Press, 2013) ${ }^{7}$

7.<http://www.europapress.es/andalucia/cultura-00621/noticia-cordoba-cultura-mas-300000personas-visitaran-patios-cordoba-dos-fines-semana-fiesta-20130510152159.html> (consultado el 17 de abril e 2015) 
El "producto de los Patios de Córdoba" muere de éxito. Su éxito, meramente comercial, se produce a costa de la pérdida del valor simbólico de este elemento cultural para los cordobeses, a quienes se aconseja amablemente desde el ayuntamiento "ir de patios" entre semana (para no ser arrollados por las hordas de turistas aclamados por turoperadores, ayuntamiento, hosteleros y declaraciones UNESCO). No importa el calendario en el que tradicionalmente se produzca. La hostelería quiere explotar este nuevo producto turístico y mantenerlos abiertos todo el año, aunque no sea primavera.

No obstante, "Ir de patio" no ha perdido todavía todo su significado y su valor identitario. Éste permanece a pesar del impulso mercantilizador -que si bien termina condicionando el desarrollo de la fiesta y la acción social que ésta implica-persisten las formas tradicionales de vivir y actuar en los patios. Sus aspectos formales se mantienen, en parte, gracias al esfuerzo incondicional de algunos de sus propietarios y habitantes. No obstante, esta fiesta se ha convertido en un espectáculo para los turistas; el valor de la macetas y latas con geranios, como elemento decorativo asequible para los más humildes que vivían en casas de vecinos, ha pasado a convertirse también en un "parque temático" muy rentable para el consumo de turistas que después de horas de espera probablemente se preguntarán el por qué de la misma, pues no tienen una relación de cuidado o de afecto por estos espacios. En 2013 el ayuntamiento de Córdoba contrató una empresa para el diseño de una aplicación móvil para controlar y distribuir las colas de turistas y una multitud de voluntarios que finalmente abandonaron la causa. Al final, gracias a la paciencia que todavía demuestran sus habitantes, expertos y conocedores de su fiesta y cuidadores de sus patios, la multitud se reguló a la manera tradicional (movidos no por el lucro sino por el afecto a este patrimonio).

Varios millones de euros entran en la ciudad durante esta fiesta. Por lo que el sacrificio de su valor cultural y simbólico resulta para algunos, en el marco de la lógica del mercado, incuestionable. El ayuntamiento ha realizado una gran inversión en la conversión de un patio en museo de la fiesta (fórmula tradicional de patrimonialización más recurrente y más alejada de la concepción procesual y viva de este patrimonio). Sin embargo, el mismo tiempo parece ser acreedor de una deuda con los propietarios para ayudarles al mantenimiento de los mismos, siendo ésta una posible medida de fomento más acorde con la continuidad de los procesos sociales. 


\subsection{EL BINOMINIO PATRMONIO-TURISMO VS. PATRIMONIO-}

SECTOR PRIMARIO EN EL DESARROLLO RURAL Y EN LA GESTIÓN MEDIOAMBIENTAL

En la mayor parte de los territorios agrícolas andaluces se está produciendo un proceso de desagrarización, orientándolos a otras actividades no agropecuarias a través de las políticas de desarrollo rural, turismo de interior o gestión medioambiental. Muchas de las estrategias de estas políticas se centran precisamente en los elementos culturales que podríamos incluir en el concepto de "patrimonio etnológico", “patrimonio inmaterial”, "paisajes culturales" convertidos ahora en "recursos" capaces de dinamizar un territorio y convertirse en el núcleo de una "marca de calidad territorial" territorios como las denominaciones de origen de productos alimentarios. Una de las estrategias actuales que podrían considerarse más coherentes en estos espacios, como afirman Lozano y Aguilar Criado (2010), es la producción de certificaciones de alimentos: las Denominaciones de Origen Protegida (DOP) o las Indicaciones Geográficas Protegidas (IGP). Estas certificaciones pretenden expresar el vínculo de estos productos con su entorno, convirtiéndose el anclaje territorial en el elemento distintivo por el que el producto agroalimentario incorpora las características del lugar (naturales y culturales), constituyendo una suma de elementos tangibles e intangibles que identifican un territorio. Las últimas reformas de la PAC para el periodo 2015-2020 demuestran que en las denominaciones de origen, a pesar de la fuerza que pueden ejercer localmente los consejos reguladores, se impone la productividad, la "eficiencia" y el bajo coste de la producción frente a la calidad del producto, como es el caso de las pasas de Málaga. La PAC ha dejado de apoyar las explotaciones minifundistas y familiares andaluzas, favoreciendo la producción de otras regiones y la gran explotación agraria en zonas de fácil manejo con maquinaria agrícola que implique bajos costes salariales, quedando fuera de las ayudas, entre otros, el olivar de montaña o pequeños cultivos minifundistas y de pendiente como el de los paseros de Málaga. Al mismo tiempo, la gran producción agroalimentaria emplea los atributos de calidad artesanal o territorial de la pequeña producción ecológica como estrategia de marketing compitiendo con ella. Por tanto, la marca de calidad territorial no puede por sí sola garantizar la continuidad de una producción agrícola que deja de ser fomentada por cuestiones de “ineficiencia” económica o falta de rentabilidad monetaria, a pesar de todos los valores sociales, culturales y

8. Para mayor información sobre la marca de calidad territorial europea puede consultarse la URL: http:// www.ruralquality.net/es/content/show/\&tid=137.html 
ambientales que esta actividad garantiza y por no poder competir con una industria agroalimentaria a gran escala que controla el mercado y las estrategias de marketing basadas en falsas etiquetas "ecológicas", "bios" o "naturales" (Ortí García, 1999).

Más allá de los discursos sobre la pretendida "sostenibilidad", lo que es fácilmente interpretable es cómo el mercado y las políticas de desarrollo rural transforman el territorio y sus elementos culturales en un objeto consumible, convirtiendo los elementos de la cultura en materias primas a transformar al gusto del consumidor urbano:

"Los territorios rurales, animados por la lógica de los tiempos, avanzan hacia un modelo productivo en el que los recursos primarios- incluidos los bienes patrimoniales de la cultura y el medio natural- parecen no adquirir su verdadera carta de utilidad más que una vez sometidos a la transformación que exige el patrón de consumo urbano. Las manifestaciones de la cultura autóctona y el paisaje, profundamente arraigadas en el entorno local, asumen su destino como objetos generadores de economía terciaria, a disposición del sector de los servicios turísticos." (Sánchez Martínez, 2010:142) ${ }^{9}$

Es decir, la falta de actividad agrícola generada por la desagrarización se tiende a cubrir con otras actividades de servicios potenciadas por las políticas de Desarrollo Rural fomentadas por los fondos de cohesión europeos y acompañadas de la PAC. La rentabilización económica del patrimonio cultural (sobre todo del patrimonio inmaterial) no puede prevalecer siempre sobre su importante valor identitario y simbólico poniéndose en peligro su importancia como instrumentos de desarrollo territorial y social.

La terciarización y turistización de la economía andaluza también puede crear una excesiva dependencia de este sector, si no se articula adecuadamente con otras actividades económicas.

"El hecho de que el visitante sea un usuario de servicios hoteleros específicos dentro del pequeño sistema rural y de que consuma prestaciones implantadas en el territorios exclusivamente para su disfrute (de alojamientos, informativas y recreativas, etc) no puede hacernos perder de vista el hecho de que, además, el turista rural es un consumidor de "cotidianeidades", un rastreador de vida y costumbres locales, mejor cuanto más ciertas." (Sánchez Martínez, 2010:151)

\footnotetext{
9. Juan Alonso Sánchez Martínez en la fecha en la que escribió este artículo era director de Cultura del Ayuntamiento de Loja y miembro del GDR del Poniente Granadino, cuyo presidente, Miguel Castellano, era también presidente de la Asociación de desarrollo rural de Andalucía (ARA) y principal interlocutor de los Grupos de Desarrollo Rural y las Consejerías de Agricultura y Pesca, Turismo.
} 
Por otro lado, los espacios relacionados con los procesos de "desagrarización" y terciarización a los que antes hacíamos referencia se han convertido en las últimas décadas en espacios protegidos por sus valores ecológicos y medioambientales ${ }^{10}$.

La política ambiental tiene una gran importancia en la planificación territorial y de desarrollo rural (frente a la política cultural). En Andalucía se producen procesos de patrimonialización de amplios territorios basados en su componente natural y biofísica olvidando las implicaciones culturales de los mismos y la siempre presente dialéctica entre naturaleza y cultura. Los documentos para planificar y regular sus usos en Andalucía (Plan de Ordenación de Recursos Naturales- PORN; Plan Rector de Uso y Gestión-PRUG) nos muestran los parques naturales de una forma simplificada, produciéndose imágenes mixtificadas de lo "natural" y a veces, en el mejor de los casos, de lo "tradicional", casi siempre material y en desuso, sin tener en cuenta la diversidad de miradas y percepciones sobre estos territorios (Florido del Corral, 2008), sobre todo la de los "camperos" (Coca Pérez, 2008). La norma en la aplicación de estas figuras de protección es no tener en cuenta a la población y sus percepciones (Quintero Morón, 2005, 2009; Pascual y Florido, 2005). En este sentido, tampoco se emplean adecuadamente algunas figuras de protección mejor adaptadas a estos espacios como las de "paisaje cultural", ni por las administraciones competentes en medioambiente ni por la competente en cultura, siendo las figuras de Lugar de Interés Etnológico (como la de la Huerta de Pegalajar o el Ruedo de Cañaveral) o de "zona patrimonial" las que más se le parecen. Una metodología más integradora y una figura que reuniera todas las competencias podría ayudar a mejorar visiones reduccionistas y mejorar la calidad de vida de amplios territorios en Andalucía.

\section{LA PARTICIPACIÓN SOCIAL DE LAS COMUNIDADES Y GRUPOS EN EL PATRIMONIO INMATERIAL: ¿TEORÍA O REALIDAD?}

El patrimonio cultural, como hemos ido analizando, es una construcción social que implica un conflicto entre diferentes apropiaciones, definiciones, delimitaciones y usos por diferentes tipos de colectivos con diversos fines, que lo emplean ya sea como objeto de investigación, como reflejo de la memoria y de la construcción de identidades, como instrumento político-institucional o como recurso económico (Sánchez Carretero, 2012).

En el "patrimonio cultural inmaterial" todas estas activaciones multifocales se han amplificado, convirtiéndose actualmente en el centro neurálgico de muchos

10. Ley 2/1989 de Inventario de Espacios naturales Protegidos de Andalucía. 
procesos de patrimonialización en diferentes contextos culturales. Esta nueva forma de entender al patrimonio también complica la "gestión" por parte de quienes, hasta el momento, gozaban de legitimación para hacerlo ("conservadores" del patrimonio como representantes del Estado). No basta saber qué es ni cómo protegerlo, sino que además es necesario saber quiénes participan en su definición e implicarlos en los procesos de gestión y decisión (Jiménez Ramírez, 2010).

La Convención coloca a la sociedad civil, a través de las "comunidades", en el centro del proceso de salvaguardia. Algunos afirman que se trata de la Convención de las Comunidades ${ }^{11}$ :

"las comunidades, los grupos y en algunos casos los individuos desempeñan un importante papel en la producción, la salvaguardia, el mantenimiento y la recreación del patrimonio cultural inmaterial, contribuyendo con ello a enriquecer la diversidad cultural y la creatividad humana" (artículo 2 de la convención).

"en el marco de sus actividades de salvaguardia del patrimonio cultural inmaterial, cada Estado Parte tratará de lograr una participación lo más amplia posible de las comunidades, los grupos y, si procede, los individuos que crean, mantienen y transmiten ese patrimonio y de asociarlos activamente a la gestión del mismo." (art. 15, idem)

No obstante, esta idea de comunidad tiene varias contrapartidas, que desde nuestro punto de vista, deberían ser tenidas en cuenta en cualquier proceso de activación patrimonial en el marco de la Convención, ya sea para la salvaguarda en el ámbito internacional a través de sus Listas (representativas, de salvaguarda urgente o registro de Buenas prácticas) o en otros contextos estatales o regionales en los que se aplican los principios de la convención:

- En primer lugar, las pretendidas "comunidades" no son homogéneas. En su delimitación no se tienen en cuenta los conflictos, tensiones y desequilibrios de poder que hay en el interior de un colectivo social relacionado con un elemento del patrimonio inmaterial. Incluso dentro de las más pequeñas se pueden producir conflictos de apropiación simbólica contrapuestas. Ello hace que también pueda producirse por parte de determinados agentes procesos de banalización, mercantilización, folklorización o espectacularización a partir de la

11. Entendidas como "redes de personas cuyo sentimiento de identidad o cuyos lazos nacen de una relación histórica compartida, anclada en la práctica de la transmisión de, o el apego hacia, su patrimonio cultural inmaterial" (Unesco-ACCU, Tokyo, 2006). 
instrumentalización política de un determinado elemento cultural. Ello también está relacionado con la asimetría en la definición de qué es patrimonio, entre quienes tienen el poder de definir y quienes "portan", lo que convierte al patrimonio en territorio de conflicto (Ariño, 2002; Mantecón, 2005), y en una expresión de poder de aquellos que deciden activar un elemento cultural como patrimonio.

- Como hemos podido observar en muchos procesos de candidaturas, ya sean en el ámbito andaluz como en el estatal o en el internacional, las comunidades no están bien definidas. En los procesos de patrimonialización de candidaturas UNESCO se aprecia una dificultad para la delimitación de las "comunidades" y los grupos que detentan la expresión cultural que muchas veces no coinciden con las comunidades que presentan su libre consentimiento en el formulario (algo que veremos en el caso del patrimonio agroalimentario analizado en este monográfico por Bortolotto). Esto puede estar debido a que las candidaturas, en algunas ocasiones, son demasiado genéricas y representan a todo un país (Japón, Corea, Francia, Italia, ..etc.) o varios países (dieta mediterránea) por lo que resulta muy complicado la participación real de una comunidad. En estos casos las iniciativas suelen venir realizadas por instituciones y la participación es difícilmente demostrable, quedándose en una declaración parcial y formal de algunos representantes. Por lo que en ocasiones no solo se inventa la tradición (Díaz y Viana, 2002), sino también a la comunidad portadora, organizándose en muchos casos campañas dirigidas a la creación de esta "comunidad" (Ej: campaña "Soy flamenco" para la candidatura del Flamenco a la Lista Representativa del Patrimonio Inmaterial de la Humanidad (inscrita en 2010)).

- La mayor parte de las veces, las comunidades son informales y no están organizadas para participar en los procesos de salvaguardia (identificación, inventario, cumplimentación de un formulario, diseño de medidas de salvaguarda...). Estas cuestiones dificultan el principio de la necesaria participación social en el ámbito del PCI de los diferentes Estados partes con sus políticas patrimoniales y la institucionalización de las mismas. Las comunidades pueden no estar organizadas formalmente y las que lo están organizadas (ONGs, asociaciones..) pueden no ser representativas de las comunidades. Estas últimas, además, pueden no tener la posibilidad o voluntad de organizarse formalmente.

- El hecho de que sean los Estados los que deben realizar las propuestas de inclusión en la Lista de Patrimonio Inmaterial, incrementa aún más el riesgo de instrumentalización política de los procesos de patrimonialización y del elemento representativo de la comunidad que la Convención pretende proteger (Bortolotto, 
2008:34, 2014; Carrera, 2009). Este papel de intermediación estatal fue muy discutido en la reunión de UNESCO en Valencia para la realización de un modelo de código ético del patrimonio inmaterial, en el que tuve la oportunidad de participar. La mayor parte de las contradicciones y manipulaciones que se dan en el marco de aplicación de la convención residen en esta intermediación estatal entre un proceso de patrimonialización local-global, como pondrán de relieve Sánchez-Carretero y Quintero Morón en su aportación, así como Cécile Duvelle. Lo que Duvelle presenta como una revolución de esta Convención (la primacía de las "comunidades" sobre la visión "experta”) es también una cuestión impracticable que la hace poco creíble (puesto que siguen siendo los Estados firmantes los entes legitimados para elevar una propuesta de candidatura a la UNESCO) con los conflictos de intereses que ello genera.

En el caso del estado español, la reciente Ley 10/2015 para la Salvaguarda del Patrimonio Inmaterial, a la hora de declarar una "Manifestación Representativa del Patrimonio Cultural Inmaterial" solo contempla "el trámite de audiencia a las comunidades portadoras del bien, a los titulares de derechos reales sobre los bienes muebles e inmuebles asociados a la $1, \mathrm{y}$ a las Administraciones autonómicas y locales del territorio en el que la manifestación tiene lugar" (art. 12.4. b de la Ley 10/2015).

No obstante, conscientes de la importancia de la "comunidad portadora" en la convención de 2003, y de la necesidad de integrarla como principal sujeto de salvaguarda, la LPCIE inventa en el preámbulo una y grande "comunidad portadora" para todas las tradiciones que se puedan declarar en el futuro: ésta es la "Nación española”. Y para ello hace referencia al preámbulo de la Constitución (aunque ésta sí reconozca la diversidad cultural del Estado- los pueblos de España-) De modo que para la LPCIE, los miembros del Estado se convierten al unísono en portadores de las tradiciones concretas de cada una de los pueblos que lo conforman:

En efecto, el Preámbulo (de la Constitución española) en su párrafo cuarto deja claro que "todos los españoles", así como los “pueblos de España” son portadores de manifestaciones culturales inmateriales: "La Nación española proclama su voluntad de proteger a todos los españoles ypueblos de España en el ejercicio de los derechos humanos, sus culturas y tradiciones, lenguas e instituciones". He aquí, pues, el todo social -el conjunto de los españoles- y las partes -los pueblos de España- concebidos como sujetos portadores simultáneamente de culturas y tradiciones, lenguas e instituciones. (Preámbulo IV. B relativo a la actividad de significación por el Estado de los valores y bienes comunes del patrimonio inmaterial.) 


\section{CONCLUSIONES}

Llegados al acuerdo de que el patrimonio es una construcción social del presente y creada por sujetos varios desde contextos culturales actuales, la aportación fundamental de la antropología en torno a la gestión del PCI debería ser dar respuesta a cómo atender de manera ordenada y completa a la multiplicidad de sus valores y dimensiones, transmitiendo todas las voces posibles de quienes se sienten representados, reflejados e identificados por él, y reforzando, o tratando de no limitar, sus propias estrategias de salvaguarda.

¿Cómo es posible convertir lo que es significativo culturalmente para un colectivo en patrimonialmente relevante sin reduccionismos ni conservadurismos de ningún tipo? En palabras de Llorenç Prats esto "constituye una estrategia espontánea y eficaz de preservación” (Prats, Ll., 2005). Las medidas de salvaguarda del PCI deberían orientarse al respaldo de las condiciones necesarias para la reproducción cultural, práctica y simbólica del mismo (Kirshenblatt-Gimblett, 2004:53), y no exclusivamente a unas de sus dimensiones, convirtiéndolo así, en un recurso político o económico o una mercancía para el consumo.

Llorenç Prats (2005) realiza una diferenciación entre patrimonio local y patrimonio localizado que es trascendental en la gestión patrimonial desde una perspectiva antropológica. Es decir, la patrimonialización, por un lado, ha de dejar de ser vertical: realizada de arriba a abajo y debe darse mayor protagonismo a la acción social: de abajo a arriba. La gestión del PCI debe ser fundamentalmente participativa y debe permitir atender a "la población, pero a toda la población, autóctona o no, y a procesos de participación activa" (Prats, 2005:28). Para ello es necesario dejar de hablar de "comunidades" en el sentido de un todo homogéneo, cohesionado y exento de conflictos.

En este contexto, la antropología podría jugar una papel fundamental por su capacidad para aplicar enfoques holísticos y técnicas participativas y para poner a la comunidad, en toda su heterogeneidad, en el centro, aplicando un concepto antropológico y no humanístico de cultura y atendiendo a la complejidad de los elementos, sin jerarquizar entre creatividad individual y colectiva; antigüedad o contemporaneidad; arte o artesanía; objetos artístico frente a procesos sociales y conocimientos; singularidad y representatividad; perpetuidad o dinamismo.

El compromiso de la antropología debería contribuir a la mejor comprensión de los discursos de los agentes que participan en la producción y transmisión de conocimientos tradicionales y aquellos que interactúan en los procesos de patrimonialización de los mismos y de las contradicciones que esta interacción 
supone y produce (Bortolotto, 2014). Se hace necesaria la mediación de técnicos cualificados para ello, capaces de realizar trabajo de campo, aplicar técnicas cualitativas y trabajar conjuntamente con la población y en ella durante el tiempo necesario. Es decir, sin ánimos corporativistas, y sin quitarle importancia a ningún otro enfoque metodológico y teórico, coincido con estos autores en que es necesario una mayor presencia de la antropología en el ámbito de la gestión patrimonial para etnografiar, documentar, analizar, diagnosticar y hacer participar a la población en la gestión patrimonial de forma que estén representadas todas las voces, todos los actores necesarios (sociales, científicos y políticos), sin crear falsas imágenes de cohesión social, sino apostando por la multiplicación de voces, de pareceres, de representaciones, de significaciones, de conflictos, para evitar mixtificaciones, banalizaciones e instrumentalizaciones reduccionistas de la cultura.

“Técnicos en gestión patrimonial que, en este caso, deben ser además, a la vez, científicos sociales capaces de trabajar en la población y con la población, en el ámbito de lo extremadamente concreto, es decir antropólogos y antropólogas formados en el trabajo de campo (...)." (Prats, 2005:28)

Por otro lado, la ampliación del concepto de patrimonio relacionado con el concepto amplio de cultura que define la antropología social no ha llevado aparejado una ampliación de acuerdos entre las entidades competentes en patrimonio y otras administraciones sectoriales. De forma que unas y otras, ante los mismos fenómenos, mantienen posturas contradictorias, y en la mayoría de los casos no son conscientes de ello. La salvaguarda del patrimonio inmaterial (una parte de la cultura en sentido antropológico) suele circunscribirse exclusivamente a los límites de acción y operatividad de la administración competente en cultura. Sin embargo, todas las administraciones con competencias en otras materias como medioambiente, agricultura y pesca, obras públicas, ordenación del territorio, vivienda, comercio, turismo, industria, costas... actúan de forma directa o indirecta sobre la cultura entendida en sentido amplio o sobre el patrimonio cultural inmaterial tal y como lo define la Convención citada (UNESCO, 2003). Por ello, se hacen necesarias herramientas adaptadas a enfoques más holísticos e integradores que pongan el acento sobre los valores simbólicos e identitarios y en el caso del patrimonio cultural inmaterial, sobre su carácter dinámico y procesual.

En definitiva, las medidas de salvaguarda al respecto deben ser el resultado de una visión amplia de la cultura y de la coordinación y concertación entre los sectores sociales, públicos y académicos interesados por los valores bioculturales de todas estas actividades en contraposición a los intereses limitados del mercado y de las instituciones que lo respaldan. 


\section{REFERENCIAS BIBLIOGRÁFICAS}

Adorno y M. Horkheimer (1998) (1944-1947) "La industria cultural. Iluminismo como mistificación de masas". En Dialéctica del iluminismo. Edit. Sudamericana, Buenos Aires.

Agudo Torrico, J (2005) "Patrimonio etnológico. Recreación de identidades y cuestiones de mercado". En Carrera Díaz, G y Dietz, G (coord). Patrimonio Inmaterial y gestión de la diversidad. Sevilla. Consejería de Cultura

Agudo Torrico, J (1999). "Cultura, patrimonio etnológico e identidad". PH: Boletín del Instituto Andaluz del Patrimonio Histórico, no 29. Sevilla, 1999a Págs. 36-45.

Alonso González, P. (2013) The Heritage Machine: A Heritage Ethnography in Maragatería. Universidad de León, León

Alsayyad, N. (ed.) (2001) Consuming tradition, manufacturing heritage: global norms and urban forms in the age of tourism. Routledge, London.

Amougou, E (2004) La question patrimoniale: De la «patrimonialisation» à lexamen de situations concrètes. Paris: L'Harmattan,

Ariño Villarroya, A (2002) “La expansión del patrimonio cultural". Revista de Occidente. vol. 250, p. 129-150.

Bendix, R. (2009) Heritage between Economy and Politics: An Assessment from the Perspective of Cultural Anthropology. En Smith, L.; Akagawa, N. (eds.). Intangible Heritage. Londres: Routledge, p. 253-269.

Bendix, R., Eggert, A., Peselmann, A. (2012) Heritage Regimes and the State. Göttingen: Universität sverlag Göttingen, 2012

BOE (2015) Ley 10/ 2015 para la salvaguarda del Patrimonio Cultural Inmaterial. «BOE» núm. 126, de 27 de mayo de 2015, páginas 45285 a 45301 (17 págs.)

BOJA (2007) Ley 14/2007 de 26 de noviembre de Patrimonio Histórico Andaluz. Junta de Andalucía. Consejería de Cultura de la Junta de Andalucía. 2005. 391. ISBN: 84-8266$567-7$

Bortolotto, C (2014) "La problemática del patrimonio cultural inmaterial". Culturas. Revista de Gestión Cultural. (1), 1-22.

Bortolotto, C (2008) "Il proceso di definición del concetto di "patrimonio culturale inmateriale". Elemento per una riflessione". En Bortolotto, C (Coord) Il patrimonio inmateriale secondo la UNESCO: analise e prospettive. Instituto Poligrçafico e zeccadellostato. Roma. 
Bouchenaki, M (2003) "The interdependency of the tangible and intangible cultural heritage". En 14th ICOMOS General Assembly and International Symposium: 'Place, memory, meaning: preserving intangible values in monuments and sites', 27 - 31 oct 2003 (vid. http://openarchive.icomos.org/468/1/2_-_Allocution_Bouchenaki.pdf).

Carrera Díaz, G. (2016). Propuesta metodológica para la documentación y gestión del patrimonio cultural inmaterial como estrategia de desarrollo social y territorial. (Tesis doctoral inédita). Universidad de Sevilla, Sevilla.

Carrera Díaz, G (2015) "La Ley 10/2015 para la Salvaguarda del PCI (2013-2014): ¿patrimonio inmaterial o nacionalismo de Estado?” En PH: Boletín del Instituto Andaluz del Patrimonio Histórico, ISSN 1136-1867, Año nº 23, No 88, 2015, págs. 21-23 20

Carrera Díaz, G (2009) "Atlas del Patrimonio Inmaterial de Andalucía. Puntos de Partidas, objetivos y criterios técnicos y metodológicos". Revista PH. Boletín del Instituto Andaluz del Patrimonio Histórico. 2009. Núm. 71. Pag. 18-42

Carrera Díaz G. y Dietz, G (2005): Patrimonio Inmaterial y Gestión de la Diversidad. Sevilla. PH Cuadernos, 17. Instituto Andaluz del Patrimonio Histórico.

Coca Pérez, A. (2008). Los camperos: Territorios, usos sociales y percepciones en un" espacio natural" andaluz. Fundación Blas Infante.

Cohen, E. (2001) "Globalización y diversidad cultural". En Informe Mundial sobre la Cultura 2000-2001. Diversidad cultural, conflicto y pluralismo. Madrid.

Consejería de Cultura. (2001) Plan General de Bines Culturales. Andalucía 2000. Consejería de Cultura. Junta de Andalucía, 2001.

Consejería de Cultura. (1993) Plan General de Bienes Culturales. Consejería de Cultura y Medio Ambiente. Junta de Andalucía. Cádiz.1993

Criado-Boado, F. (1996) "Hacia un modelo integrado de investigación y gestión en Patrimonio Histórico: la cadena interpretativa como propuesta”. Boletín del Instituto Andaluz del Patrimonio Histórico. 1996, vol. 16, p. 73- 78.

Csergo, Julia, (2011) Le "Repas gastronomique des Français » à l'Unesco: éléments d’une inscription au patrimoine culturel immatériel de l'humanité, OCHA.

Díaz G. Viana, L. (2002) Los guardianes de la tradición. Ensayos sobre la “invención” de la cultura popular. Sendoa, Guipúzcoa.

Escalera Reyes, J (2011) "Public Participation, Socio-ecological Resilience and Environmental Restoration: Lessons from two contrasting cases from Andalusia and Costa Rica". En D. Egan, E. E. Hjerpe y J. Abrams (eds.), Human Dimensions of EcologicalRestoration. IntegratingScience, nature, and Culture. Washington: Island Press. 
Fernández de Paz, Esther; Agudo Torrico, Juan (eds.) (1999) Patrimonio cultural y museología. Santiago de Compostela, FAAEE-Asociación Galega de Antropoloxía,

Florido del Corral, David (2008). "La Reserva de la Biosfera Intercontinental del Mediterráneo (Rbim). Nuevas Herramientas para Viejos Problemas". XI Congreso de Antropología de la Federación de Asociaciones de Antropología del Estado Español (FAAEE) ¿Retos Teóricos y Nuevas Prácticas? Donosti-San Sebastián. Ankulegi, p. 265-288.

Gascón, J. (2009). El turismo en la cooperación internacional. De las brigadas internacionalistas al turismo solidario. Espagne: Icaria, Antrazyt.

Greenwood, D.J. (1997) Culture by the Pound: An Anthropological Perspective on Tourism as Cultural Commoditization. En Valene L. Smith (ed.). Hosts and Guests: The AnthropologyTourism. Philadelphia: University of Pennsylvania Press, 1977, pp. 129-138. Hafstein, Valdimar Tr. (2011) “Célébrer les différences, renforcer la conformité". En ChiaraBortolotto (dir.), Le patrimoineculturelimmatériel: enjeuxd'unenouvellecatégorie. Paris: Maison des sciences de l'homme, p. 75-97.

Heinich, N (2009). La Fabrique du patrimoine. De la cathédrale à la petitecuillère. Paris: Éditions de la Maison des sciences de l'homme/ministère de la Culture et de la Communication, coll. «Ethnologie de la France».

Henríquez Sánchez, T. (2011) Lo que el ojo no ve. Políticas de lo inmaterial. Revista Atlántida, 3; diciembre, pp. 193-206; ISSN: 556-4924. Heritage. Girona: ICRPC, 2010, pp. 9-24.

Hernández Ramírez, Javier (2004) "La Construcción Social del Patrimonio: Selección, Catalogación e Iniciativas para su Protección. el Caso del Palacio del Pumarejo" Pag. 8495. En ntropologia y Patrimonio: Investigación, Documentación e Intervención. Santander (ESPAÑA). Instituto Andaluz del Patrimonio Histórico. ISBN 84-8266-369-0

Hewison, R. (1987). The Heritage Industry. Britain in a Climate of Decline. London, Methuen.

Instituto del Patrimonio Cultural de Espala (IPCE) (2011) Plan Nacional para la Salvaguarda del Patrimonio Cultural Inmaterial

Jiménez Ramírez, M. B. (2010) La construcción del discurso del patrimonio en la Huatápera de Uruapan. Tesis de maestría en Comunicación de la Ciencia y la Cultura, Guadalajara. Iteso.

Junta de Andalucía (2010) Ley 9/2010, de 30 de julio, de Aguas para Andalucía. Recuperado de http://www.juntadeandalucia.es/boja/2010/155/1 
Junta de Andalucía (1991) Ley 1/91 de 3 de julio de Patrimonio Histórico Andaluz.

Kirshenblatt-Gimblett, B. (2004). El patrimonio inmaterial como producción metacultural. Museum International 221-222: 52-57.

Lacarrieu, M. (2008) “ ¿Es necesario gestionar el patrimonio inmaterial? Notas y reflexiones para repensar las estrategias políticas y de gestión". En Boletín Gestión Cultural, 17: 2-26.

Lozano Cabedo, C y Aguilar Criado, E. (2010) "Natural, tradicional y de la Tierra. La promoción de la calidad agroalimentaria en los nuevos espacios rurales andaluces". En Patrimonio cultural en la nueva ruralidad andaluza (pp. 126-139). Instituto Andaluz del patrimonio Histórico. Consejería de Cultura

Moreno Navarro, I (2002) "Cultura andaluza, patrimonio cultural y políticas de patrimonio" Demófilo. Revista de cultura tradicional. Tercera Época. Número 1, primer semestre. Fundación Machado. Sevilla.

Ortí García, C (1999) “Consumiendo tradición: elementos patrimoniales y locales en la publicidad alimentaria”. En Fernández de Paz, E; Agudo Torrico (ED) Patrimonio Cultural y museología. Significados y contenidos. Santiago de Compostela. Asociación Galega de antropología, 1999. pp 127-139

Padiglione, V. (1999). "El efecto marco: las mediaciones del patrimonio y la competencia antropológica" En (VVAA) Patrimonio etnológico: nuevas perspectivas de estudio (pp. 212-227). Instituto Andaluz del Patrimonio Histórico.

Pascual Fernández y Florido del Corral (2005) ¿Protegiendo los recursos? Áreas protegidas, poblaciones locales y sostenibilidad. Sevilla: Fundación Monte.

Pérez, Beatriz (2006) “Turismo y Representación de la cultura. Identidad Cultural y resistencia en -comunidades andinas de Cuzco". Anthropologica 24:29-50.

Plata García, F y Rioja López, Concha (2005) “El efecto dominó en el patrimonio etnológico", en Carrera Díaz, Gema y Dietz, Gunther, (coords.) Patrimonio inmaterial y gestión de la diversidad. Junta de Andalucía, Sevilla, 2005, pp. 181-195.

Prats, $\mathrm{Ll}$ (2005) “Concepto y gestión del patrimonio local”. Quaderns-e de l'Institut Català d'Antropologia, (9).

Quintero Morón, V (2009) Los sentidos del Patrimonio. Alianzas y conflictos en la protección del patrimonio etnológico andaluz. Fundación Blas Infante.

Quintero Morón, V (2005) "El patrimonio intangible como instrumento para la diversidad cultural ¿una alternativa posible?” En Carrera Díaz, Gema y Dietz, Gunther 
(2005) Patrimonio Inmaterial y Gestión de la Diversidad. Sevilla.

Rioja López, C (2006 ) “Artesanía y Administración. Encuentros y desencuentros”. Boletín del Instituto Andaluz del Patrimonio Histórico, 59: 76-85.

Rioja López, C (1996) "Reflexiones en torno a la cultura inmaterial y su gestión patrimonial en la Comunidad Autónoma Andaluza”. Boletín del Instituto Andaluz del Patrimonio Histórico, Número 16, 1996, pp. 79-84.

Rosas Mantecón, A.(1999) "La participación social en las nuevas políticas para el patrimonio cultural". Patrimonio etnológico: nuevas perspectivas de estudio (pp. 34-51). Instituto Andaluz del Patrimonio Histórico.

Salvador Clavé, A y González Reverté, F (2007) A propósito del turismo: la construcción social del espacio turístico. Editorial UOC,

Sánchez-Carretero, Cristina (2012) "Hacia una antropología del conflicto aplicada al patrimonio". Geopolíticas patrimoniales: De culturas, naturalezas e inmaterialidades. Una mirada etnográfica. B. Santamarina (Ed.), pp. 195-210. Editorial Germania, Colección Antropológicas, Valencia.

Sánchez Martínez, Alonso (2010) “Territorio turístico y nueva ruralidad”. En Patrimonio cultural en la nueva ruralidad andaluza. (pp. 190-217). Instituto Andaluz del Patrimonio Histórico. Cuadernos Técnicos

Santamarina Campos, Beatriz (2011) "Desvistiendo lo inmaterial. Viejos ropajes para tiempos ávidos: la (s) disputa (s) por la definición del patrimonio (s)". Actas del XII Congreso de Antropología (pp. 1409-1419).

Sierra Rodríguez, J. C. Pereiro, X. (2005). Patrimonio cultural: politizaciones y mercantilizaciones. X Congreso de Antropología. Fundación El Monte.

Smith, L (2006) Uses of Heritage. London \& New York, Routledge

\section{UNESCO}

(2006) Reunión de expertos sobre la participación de las comunidades en la Salvaguardia del Patrimonio Cultural Inmaterial. Tokio, Japón

(2003) Convención para la Salvaguardia del Patrimonio Cultural Inmaterial. París, Octubre.

(1989) Recomendaciones para la Salvaguardia de la Cultura Tradicional y Popular.

(1994) "Estrategia Global” y estudios temáticos para una Lista del Patrimonio Mundial representativa (20-22 de junio de 1994) 